\title{
Low-altitude signatures of the cusp and flux transfer events
}

Article

Published Version

Lockwood, M. and Smith, M. F. (1989) Low-altitude signatures of the cusp and flux transfer events. Geophysical Research Letters, 16 (8). pp. 879-882. ISSN 0094-8276 doi: https://doi.org/10.1029/GL016i008p00879 Available at https://centaur.reading.ac.uk/38872/

It is advisable to refer to the publisher's version if you intend to cite from the work. See Guidance on citing.

Published version at: http://dx.doi.org/10.1029/GL016i008p00879

To link to this article DOI: http://dx.doi.org/10.1029/GL016i008p00879

Publisher: American Geophysical Union

All outputs in CentAUR are protected by Intellectual Property Rights law, including copyright law. Copyright and IPR is retained by the creators or other copyright holders. Terms and conditions for use of this material are defined in the End User Agreement.

\section{www.reading.ac.uk/centaur}

\section{CentAUR}

Central Archive at the University of Reading

Reading's research outputs online 


\section{LOW-ALTITUDE SIGNATURES OF THE CUSP AND FLUX TRANSFER EVENTS}

Mike Lockwood

Rutherford Appleton Laboratory, Chilton, UK

Mark F. Smith

Southwest Research Institute, San Antonio, USA

Abstract The usual interpretation of a flux transfer event (FTE) at the magnetopause, in terms of time-dependent and possibly patchy reconnectIon, demands that it generate an ionospheric signature. Recent ground-based observations have revealed that auroral transients in the cusp/cleft region have all the characteristics required of FTE effects. However, signatures in the major avallable dataset, namely that from low-altitude polar-orbiting satellites, have not yet been identified. In this paper, we consider a cusp pass of the DE-2 spacecraft during strongly southward IMF. The particle detectors show magnetosheath ion injection signatures. However, the satellite motion and convection are opposed, and we discuss how the observed falling energy dispersion of the precipitating ions can have arisen from a static, moving or growing source. The spatial scale of the source is typical of an FTE. A simple model of the ionospheric signature of an FTE reproduces the observed electric and magnetic field perturbations. Precipitating electrons of peak energy $-100 \mathrm{eV}$ are found to lie on the predicted boundary of the newly-opened tube, very similar to those found on the edges of FTEs at the magnetopause. The injected ions are within this boundary and their dispersion is consistent with 1 ts growth as reconnection proceeds. The reconnection potential and the potential of the induced ionospheric motion are found to be the same $(\approx 25 \mathrm{kV})$. The scanning imager on DE- 1 shows a localised transient auroral feature around $\mathrm{DE}-2$ at this time, simflar to the recent optical/radar observations of FTEs.

\section{Int roduction}

The cusp is a region where magnetosheath plasma is injected into the magnetosphere and Ionosphere. The restricted extent of this source and the convection electric field cause energy dispersion of lons observed in the ionosphere (see discussion by Smith et al. 1989). A Flux Transfer Event (FTE) is a signature in the magnetic field seen near the magnetopause, interpreted as resulting from time-dependent reconnection (Russell and Elphic, 1978). Inside an FTE there is a layered mixing of magnetosphere and magnetosheath plasma. Recently Menietti and Burch (1988) have shown cusp injections have a similar spatial extent as FTEs and suggested the two phenomena may be linked.

Observations by ground-based optical photometers and T.V. all-sky cameras have revealed transient, short-11ved arcs (in both $630 \mathrm{~nm}$ and

Copyright 1989 by the American Geophysical Union.

Paper number $89 \mathrm{GL} 01352$.

0094-8276/89/89GL-01352\$03.00
$557.7 \mathrm{~nm}$ emissions) occurring throughout the dayside auroral oval when the IMF is southward, superposed on the persistent "cleft" aurora (630nm on1y). Recently, Lockwood et al. (1989) have shown that each optical event is accompanied by a transient flow burst of ionospheric plasma, and that considerable potentials (20-55 kV) were applied across the field-of-view of the EISCAT radar. Sandholt et al. (1989) have studied a pass of the HILAT satellite through one of these events and found particle injection signatures and fllamentary field-aligned currents. These transient events have been shown to be fully consistent with magnetopause FTEs: in their occurrence (during southward IMF only); motion (west or east, depending on IMF $B_{y}$, before turning into the polar cap); field-aligned currents (oppositely directed matched pair); ionospheric flow (twin vortical); scale size (few hundred kilometres); and potentials. In this paper, we study cusp-like fon injection using a pass of the $\mathrm{DE}-2$ satellite. In the light of the above observations, we consider the injection in terms of an FTE.

\section{DE- 2 Observations}

Figure 1 shows data from a northern hemisphere pass of DE-2 on 22 October, 1981 at a height of $900 \mathrm{~km}$. Data are shown from the Low-Altitude Plasma Instrument (LAPI), Ion Drift Meter (IDM) and the magnetometer (MAG-B). For more details of these and DE-l data see Smith et al. (1989). The IMF was observed by ISEE- 3 to turn southward at about 08 UT on this day following a 10-hour period when it was northward. Allowing for the predicted propagation delay, the near-Earth IMF was strongly southward ( $\left.B_{2} \simeq-10 n T\right)$ at the time of this event. The $B_{y}$ component was large and positive $(\approx+10 \mathrm{nT})$.

Pahel (a) shows the fluxes of electrons of energy greater than $35 \mathrm{keV}$ at pitch angles of $0^{\circ}$ ( $1 \mathrm{n}$ blue) and $90^{\circ}$ (in red). The anisotropic fluxes (showing a loss cone in the pitch angle distribution) observed before 09:55:20UT define the flux tubes as being closed: subsequently the lower, isotropic fluxes indicate open fleld lines. Panels (b) and (c) are energy-time spectrograms of precipitating tons and electrons, respectively.

The ion data appear to show the classic cusp ion injection signature with lower energy ions observed as the satellite moves poleward. However, panel (e) shows that the RAM component of the drift, $v_{r}$, is positive when the ions are observed (09:55:30-09:55:48), 1.e. in the opposite direction to the satellite motion. For this case, a steady-state two dimensional time-offlight model predicts ion energy rising with time, the opposite to what is observed. Hence we must consider the third spatial dimension and/or temporal variations. The satellite path is northeastward, and the cross and ram drifts (panels $d$ 
(b)
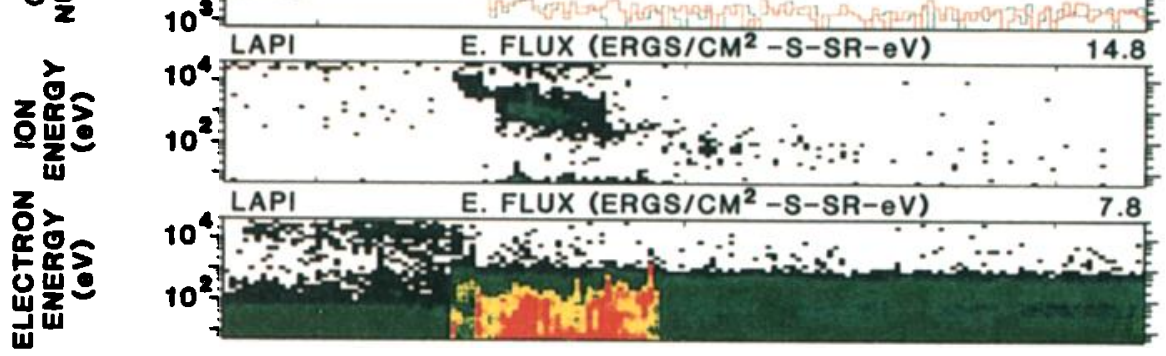

(c)

(d)
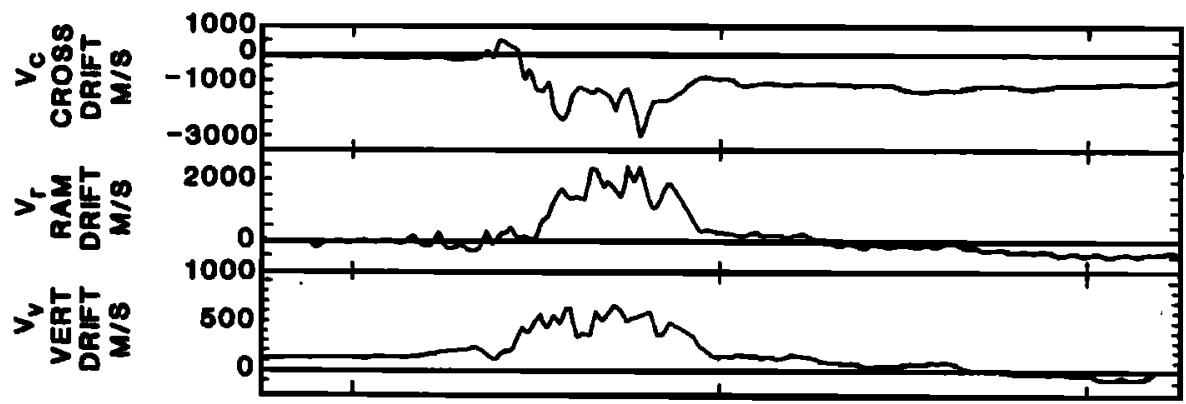

(g)

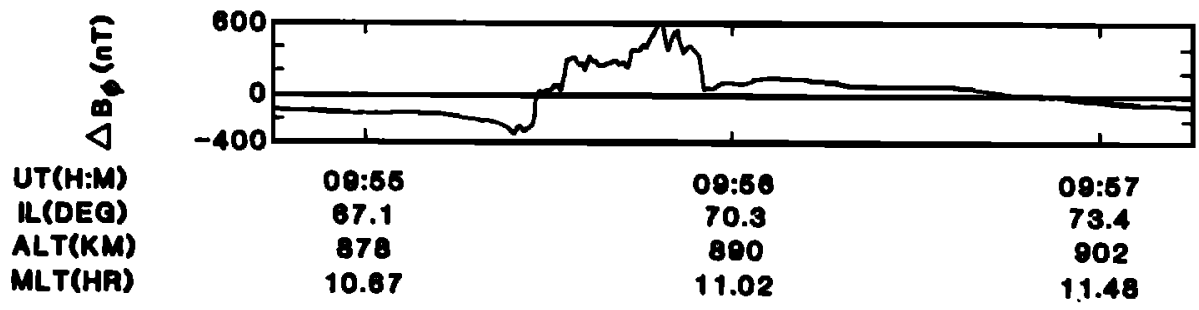

F1g. 1. Data from DE-2 on 22 October, 1981.

and $e$ of fig. 1) give plasma flow just south of westward when the injected ions are seen. This motion is found to be aligned with the morningsector polar cap boundary, as defined by the DE- 1 imager (discussed later), and is consistent with reconnection for the observed IMF $B_{>}>0$. Panels (f) and (g) show that large upward flows of lonospheric lons and intense fleld-aligned currents (the latter seen by their effect on the eastward component of the magnetic field, $\Delta B_{\phi}$ ) are also present near the injected lons.

Hodograms of the fleld-perpendicular disturbance of the magnetic field observed by MAG-B reveal that the fleld rotated first from southwestward to south-eastward via southward. Subsequently, a weaker perturbation was superposed with a rotation in the opposite sense from northeastward to north-westward (Smith et a1., 1989). These rotations occur during the two major changes in $\Delta \mathrm{B}_{\sigma}$ shown in Figure $\mathrm{l}(\mathrm{g})$ and show that the satelilte passed to the east of a pair of filamentary field-aligned currents, the upward current being roughly $150 \mathrm{~km}$ poleward of the downward one. If these two form a matched pair, the satellite must have passed considerably closer to the downward current, as the magnetic perturbation it caused was greater.

S1mple Model of FTE Effects

We employ the model of FTE field perturbations in the lonosphere by Southwood (1987), in which momentum is transferred to the ionosphere by a pair of oppositely-directed field-aligned currents on the flanks of the newly-opened flux tube. Part (a) of figure 2 shows the lonospherlc footprint of a circular tube. Also shown is a snapshot of the lonospheric flow equipotentials, in the frame fixed with respect to the Earth. If it is assumed that the satellite intersects the open tube (as is required $1 \mathrm{f}$ the fon injection 18 indeed due to an FTE) between $09: 55: 30$ and $09: 55: 48$, the mean cross and ram drifts for this period do not show any consistent rotational flow (twisting). This being the case, the Southwood FTE model applies, for which the velocity at all points within the event is that of the event itself. The means of $v_{c}$ and $\mathrm{v}_{\mathrm{r}}$ define this event velocity to be $2.5 \mathrm{~km} \mathrm{~s} \mathrm{~s}_{1}$, in a direction at $138^{\circ}$ to the satellite orb1t. The straight line in the figure shows a satellite locus, relative to the open flux tube, for this event velocity and the satellite velocity of 7.4 $\mathrm{km} \mathrm{s} \mathrm{s}^{-1}$. The vectors $\bar{V}_{\mathrm{c}}$ and $\overline{\mathrm{V}}_{\mathrm{r}}$ show the directions of the measured cross and ram drifts.

With the above assumptions, the model of the event intersection is uniquely determined by one variable, the distance of closest approach of the satellite to the event centre. Th1s has been chosen to make the satellite intersect the open tube yet pass to the east of both current filaments. The variations of $v_{c}$ and $v_{r}$ shown in figure 2 have many of the features of the observations. It is noticable that the effect on closed field lines is much smaller than predicted and a cross drift persists on open field lines after the event. These differences can be quantitatively explained by generalising the shape of the event from a circle, by considering the event as growing in size at it propagates, or by superposing the event on a background flow. 


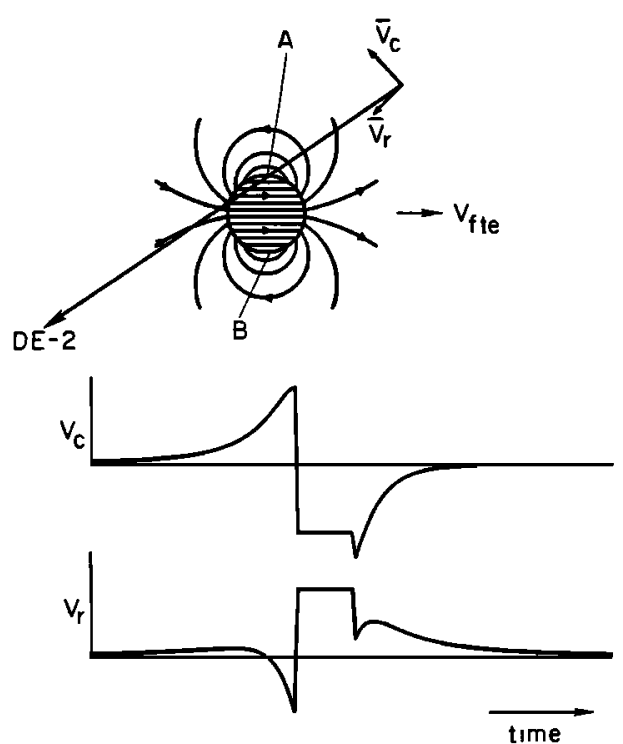

Fig. 2. Model flow components $\bar{v}_{c}$ and $\bar{v}_{r}$ as a function of time for an intersection of a circular open flux tube (velocity $\bar{V}_{1}=2.5 \mathrm{~km} \mathrm{~s}^{-1}$ ) and $\mathrm{DE}-2$ (velocity $7.4 \mathrm{~km} \mathrm{~s}^{-1}$ at $13 \mathrm{~g}^{\circ}$ to $\overline{\mathrm{v}}_{\mathrm{p}}$ ) shown at top of figure, which also gives a snapshot of induced flow equipotentials.

The boundaries of the event defined by this model place the injected ions within the newlyopened flux tube and the bursts of precipitating electrons [fig. 1 (c)] on the boundaries. These are simflar to the streaming electrons found on the edges of FTE open flux tubes at the magnetopause and are explained in the FTE models by Southwood et al. (1988) and Scholer (1988) as arising from continuing, slower reconnection. An 18-second intersection with the open flux tube gives an event diameter of $170 \mathrm{~km}$ for this model circular tube and the path shown in Figure 2 . Integrating the observed electric field across this diameter yields a potential of $25.5 \mathrm{kV}$. The above discussion provides just one of a number of possible interpretations of the flow data in terms of an FTE. In the next section we discuss how other data, particularly that from the magnetometer, are also consistent with the intersection described in Figure 2.

\section{Discussion of FTE Model}

From the particle data, we estimate the heightintegrated Pedersen conductivity in the injection event to be 10 mhos, giving total field-aligned currents of $2.5 \times 10^{5}$ A for the electric field inside the event observed by IDM. The peak magnetic perturbations observed place the downward and upward currents 33 and $100 \mathrm{~km}$, respectively, to the west of $D E-2$ at the times of observation. Using the direction of event motion derived from the IDM data, a simple geometric construction shows the current filaments to be $170 \mathrm{~km}$ apart and to be moving at $2.3 \mathrm{~km} \mathrm{~s}^{-1}$. These values are very similar to those derived in the previous section. Hence the IDM and MAG-B data are consistent with the Southwood (1987) model of the Ionospheric signature of an FTE, with an oppositely-directed pair of fleld-aligned currents on the flanks of a moving, newly-opened flux tube.

The events described by Lockwood et al. (1989) were observed under very similar IMF conditions and were first observed on the equatorward boundary of the persistent cleft aurora (moving rapldly westward) and faded $1-2^{\circ}$ poleward of it after a lifetime of up to $15 \mathrm{~min}$. Evidence that the event described here is accompanied by a similar auroral event comes from the scanning global 1mager on DE-1. Figure 3 shows the geographic latitude of peak auroral emissions at three geographic longitudes as a function of time. DE-2 intersected the event near geographic co-ordinates $\left(68^{\circ}, 341^{\circ}\right)$. The scans show a general equatorward motion of the oval, consistent with an expanding polar cap following the southward turning of the IMF. Superposed on this general trend is a silght equatorward motion seen at longitudes $0^{\circ}$ and $30^{\circ}$ (i.e. east of $\mathrm{DE}-2$ ) at some time between $09: 45$ and 09:55, followed by a poleward motion between 09:55 and 10:05. The event does not appear to reach longitude $330^{\circ}$. Hence the imager data are consistent with a transient event occuring around $\mathrm{DE}-2$, at the time of the ion injection event, similar to those recently reported from the ground.

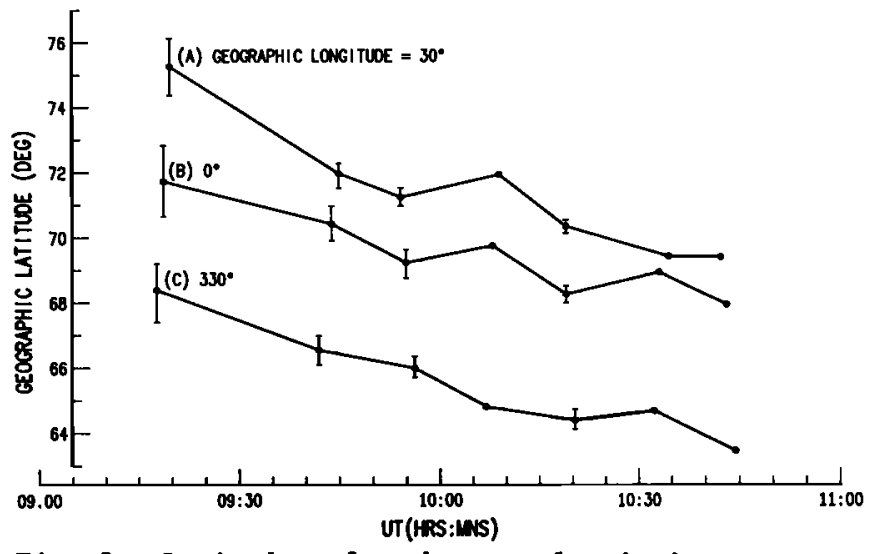

Fig. 3. Latitudes of peak auroral emissions as a function of time at 3 longitudes, from the scanning Imager on DE-1 on 22 october 1981.

Discussion of Ion Injection

F1gure 4 shows schematically three ways in which the observed ion dispersion could have arisen. In all three cases, the ionospheric projection of the injection region required is shown (roughly to scale) relative to the path of $D E-2$, which observed injected lons between points $A$ and $B$. Figure 4(a) shows how the dispersion can arise from a static source, of dimensions roughly $3 \mathrm{R}_{\mathrm{E}}$ by $0.5 \mathrm{R}_{\mathrm{E}}$, angled at $30^{\circ}$ to the convection velocity vector, $\vec{V}_{p}$. These dimensions are calculated from the lons' time of flight by using a simple model of the magnetic fleld with the magnetopause at $10 R_{E}$. Spatial variations in $\bar{V}_{p}$ between a static source and $\mathrm{DE}-2$ can be invoked ${ }^{\mathrm{p}}$ to give a similar result. The second possibility, $b$, is of a region $0.5 R_{E}$ long, perpendicular to $\vec{V}_{p}$, moving towards $D E-2$. To give the falling ion energles observed, the injection region at the magnetopause must be approaching the satellite at a speed exceeding the local convection speed.

In this paper, we do not wish to discuss the likelihood of the flow geometry and source motion 

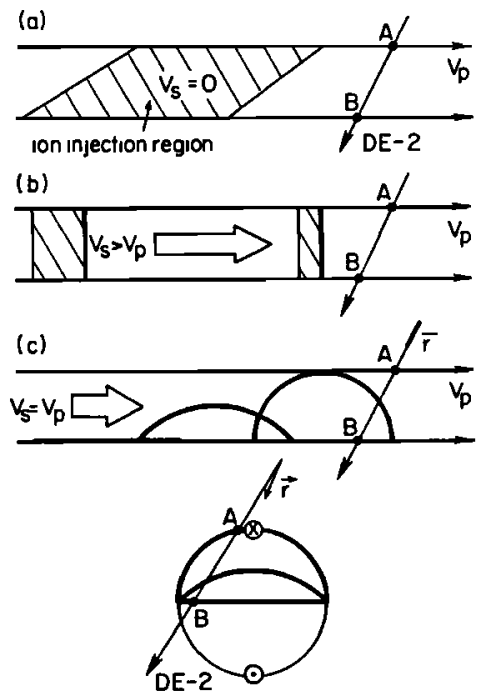

Fig. 4. Schematic of three models of ion injection giving falling ion energies at $D E-2$ between $A$ and $B: V_{S}$ is the velocity of the ionospheric projection of the source region, $\bar{v}_{p}$ is the fonospheric convection velocity.

required by these static and moving source models, respectively. Rather, we wish to point out that the particle data are consistent with a third model: that of a growing source region. This model, unlike the two mentioned above, offers an explanation of the drifts, field-allgned currents and auroral motions observed. Figure $4(c)$ shows how the observed dispersion could arise from a motion of the injection region perpendicular to $V$. In effect, DE-2 sees more recently injected ibns first (higher energies at $A$ ) as the injection region is propagating equatorward while the satellite moves poleward. We imagine the injection to occur on the leading edge of a region of newly-opened flux as it expands, due to a burst of reconnection. The lowest part of figure 4 shows the same evolution of the injection line and newly-opened flux regions, this time in the frame moving with the open flux tube. Allowing for times of flight, the lowest energy (i.e earliest injected) Ions seen by $D E-2$ between points $A$ and B show the growth occurred over 67 seconds - a reasonable reconnection time for an FTE. Assuming the flux tube is circular after this growth, a total of $1.53 \times 10^{6} \mathrm{~Wb}$ has been added, giving a reconnection potential of $23 \mathrm{kV}$. This is strikingly similar to the potential of $25 \mathrm{kv}$ previously found to be associated with the motion of the event. To give the observed highest energy lons, the injection must last for 200 seconds. This figure is found to be roughly the same for all points between $A$ and $B$, and in this model, is the time to empty the newly-opened tube of mixed magnetosphere and magnetosheath ions. Note that precipltating lons of energies above about $10 \mathrm{keV}$ can be seen in figure 1 (b) until 09:55:50, 1.e. on closed and on what we suggest here are the newlyopened flux tubes of an FTE. None are seen on the open field lines after 09:55:48. It is, at first sight, surprising that lons, presumably of magneto-spheric origin, continue to precipitate after reconnection. However, the magnetic "bottle" which can trap such ions around the minimum in the magnetic field at middle latitudes of cusp field lines will not be lost until the field line is straightened. Hence ions scattered from large pitch angles will precipitate until the equatorial magnetic mirror ceases to be effective. The combination of energetic electron isotropy and $10 \mathrm{keV}$ precipitating lons indicates the injection region is indeed a newly-reconnected flux tube.

\section{Conclusions}

The ion dispersion, precipitating electrons and electric and magnetic field perturbations observed by $\mathrm{DE}-2$ during a dayside auroral pass are shown to be consistent with, and we1l explained by, a model of the reconnection and motion of an FTE flux tube. The potentials associated with the growth and motion of the event are found to be the same, as required by the Southwood FTE model. We note that consideration of the particle data from the region inside the newly-opened flux tube alone, the ion injection would have been termed the "cusp" and could be explained in terms of steady-state convection and particle injection, provided a three-dimensional model is used. However, this does not explain the fllamentary fleldaligned currents, the electron precipitation structure and the transient auroral motions observed during this event, which strongly suggest temporal variations in both convection and injection.

Acknowledgements. The authors are grateful to J. D. Winningham, R.A. Heelis, J.A. Slavin and J.D. Craven for provision of data and discussions of the work, for which we also thank D.J. Southwood, S.W.H. Cowley and M.P. Freeman. This research is supported by NASA grant NAGW-1638.

\section{References}

Lockwood, M., P.E. Sandholt and S.W.H. Cowley, Dayside auroral activity and magnetic flux transfer from the solar wind, Geophys Res. Lett, $16,33,1989$.

Mentetti, J.D., and J.L. Burch, Spatial Extent of the Plasma Injection Region in the CuspMagnetosheath Interface, J. Geophys. Res., 93, $105,1988$.

Russeli, C.T. and R.C. Elphic, Inital ISEE magnetometer results: magnetopause observations, Space Sci. Rev., 22, 681, 1978.

Sandholt, P.E., et al., Electro-dynamics of the polar cusp ionosphere - A case study, J. Geophys. Res., in press, 1989.

Scholer, M. Magnetic flux transfer at the magnetopause based on single $X-1$ ine bursty reconnection Geophys. Res. Lett., 15,291, 1988.

Smith, M.F., et al., Spacecraft Observations of Plasma Injections and Associated Phenomena near the cusp, J. Geophys. Res., submitted, 1989.

Southwood, D.J. The ionospheric signature of flux transfer events, J.Geophys. Res., 92,3207, 1987.

Southwood, D.J., C.J. Farrugia and M.A. Saunders, What are flux transfer events?, Planet. Space Sc1., 36, 503, 1988.

M. Lockwood, Rutherford Appleton Laboratory, Chilton, Didcot, Oxon., OXI1 OQX, U.K. M.F. Smith, Southwest Research Institute, P.O Drawer 28510 , San Antonio, Texas 78284 , U.S.A.

(Received: 13 April 1989;

revised: 16 May 1989 ;

accepted: $9 \mathrm{July} 1989)$ 